(2) Open Access Full Text Article

\title{
Lumbar spinal stenosis attributable to tophaceous gout: case report and review of the literature
}

\author{
This article was published in the following Dove Press journal: \\ Therapeutics and Clinical Risk Management \\ 28 September 2017 \\ Number of times this article has been viewed
}

\author{
Wei Wang \\ Qingbo Li \\ Lei Cai \\ Weijun Liu \\ Department of Orthopaedics, $\mathrm{Pu}$ \\ Ai Hospital, Tongji Medical College, \\ Huazhong University of Science and \\ Technology, Wuhan, People's Republic \\ of China
}

Objectives: Tophaceous gout seldom affects the axial skeleton. Symptoms vary according to the differential localization of urate deposits and the diagnosis is often delayed. Here, we report an unusual case of lumbar spinal stenosis caused by extradural tophaceous deposits.

Methods: We retrospectively reviewed a case of a patient with tophaceous gout of the lumbar spine and reviewed the relevant literature.

Results: A 62-year-old man with a 2-year history of lower back pain and a 3-month history of lower limb radiation pain and intermittent claudication was admitted. After laboratory and imaging investigations he underwent surgical decompression and stabilization. Histological analysis of the extracted specimen confirmed that it was gouty tophus. The patient's symptoms improved progressively after the operation. He recovered very well with no complications.

Conclusion: The mechanism associated with axial gout is not yet clear. Obesity, inactivity, and previous degenerative disc disease may be the risk factors for spinal tophus. The clinical symptoms are diverse according to the differential localization of urate deposits. It is not easy to diagnose this disease radiographically by routine radiological examination. Analysis of a biopsy specimen is definitely the only way to confirm diagnosis. Surgical treatment should be considered in patients with spinal gout who are experiencing neurological deterioration.

Keywords: tophaceous gout, spinal gout, case report

\section{Introduction}

Although the incidence of gout in the recent years is getting higher in China due to changes in diet, tophaceous gout uncommonly affects the axial skeleton. Lumbar spinal stenosis secondary to epidural gouty tophi has been reported occasionally. We present a case of a patient with tophaceous gout of the lumbar spine and reviewed the relevant literature.

\section{Case report}

A 62-year-old man was admitted with a 2-year history of lower back pain. Radiating pain to the right lower limb and intermittent claudication occurred 3 months earlier. These symptoms progressed gradually until the time of admission. He had a 4-year history of gouty arthritis for which he received medical care occasionally. There was no history of spinal injury, fever, chills, weight loss, or night sweats. As the patient had no mental retardation, aggressive behavior, muscle spasms, or other symptoms of central nervous system developmental disorders, purine enzymopathy like deficiency of hypoxanthine-guanine phosphoribosyl transferase could be excluded. The family history was noncontributory, with all the family members being negative for gout.

Physical examination revealed tenderness on the L2-L4 spinous process with decreased activity of lumbar vertebrae. Hypoesthesia was detected in both lower limbs
Correspondence: Weijun Liu Department of Orthopaedics, Pu Ai Hospital, Tongji Medical College, Huazhong University of Science and Technology, 473 Hanzheng Street, Wuhan 430033, People's Republic of China

Tel +86I3986I4062I

Email iamliu2003@I63.com
Therapeutics and Clinical Risk Management 2017:13 1287-1293

1287 
at the L3-L5 dermatomes areas, with the right side being more severe. The muscle strength of the lower limb was normal. The right straight leg raising sign was positive. The Babinski sign was not detected. No joint swelling or tophi were found over the elbows, knees, ankles, and toes, except one gouty tophus, which developed on the right little finger 1 month earlier (Figure 1).

Laboratory investigations revealed that the serum uric acid levels were $535 \mu \mathrm{mol} / \mathrm{L}$ (normal range: 208-428 $\mu \mathrm{mol} / \mathrm{L}$ ). Complete blood count and urinalysis on the day of admission were within normal limits. Erythrocyte sedimentation rate and C-reactive protein were also within the normal ranges. Blood biochemical analysis showed: $\mathrm{Ca} 2.33 \mathrm{mmol} / \mathrm{L}$, inorganic P $1.27 \mathrm{mmol} / \mathrm{L}, \mathrm{Mg} 0.83 \mathrm{mmol} / \mathrm{L}, \mathrm{K} 3.8 \mathrm{mmol} / \mathrm{L}, \mathrm{Na}$ $142 \mathrm{mmol} / \mathrm{L}$, and alkaline phosphatase $83 \mathrm{U} / \mathrm{L}$. All of these findings were within the normal range of our laboratory.

Imaging examinations of plain X-ray films showed no obvious abnormality of the lumbar spine except slight degenerative lumbar scoliosis (Figure 2). Computed tomography (CT) (Figure 3) showed a partially calcified, round mass in the spinal canal at the level of L3/4 with a gas-like low-density nodule in the interior. The mass size was $1.1 \times 1.1 \times 0.7 \mathrm{~cm}$. According to the axial tomography, the mass was situated in the right part of the spinal canal (Figure 3B). Spinal stenosis was found at the L3/4 accordingly.

A lumbar spine magnetic resonance imaging (MRI) examination showed an abnormal round epidural collection at the L3/4 level, compromising the spinal canal and causing cauda

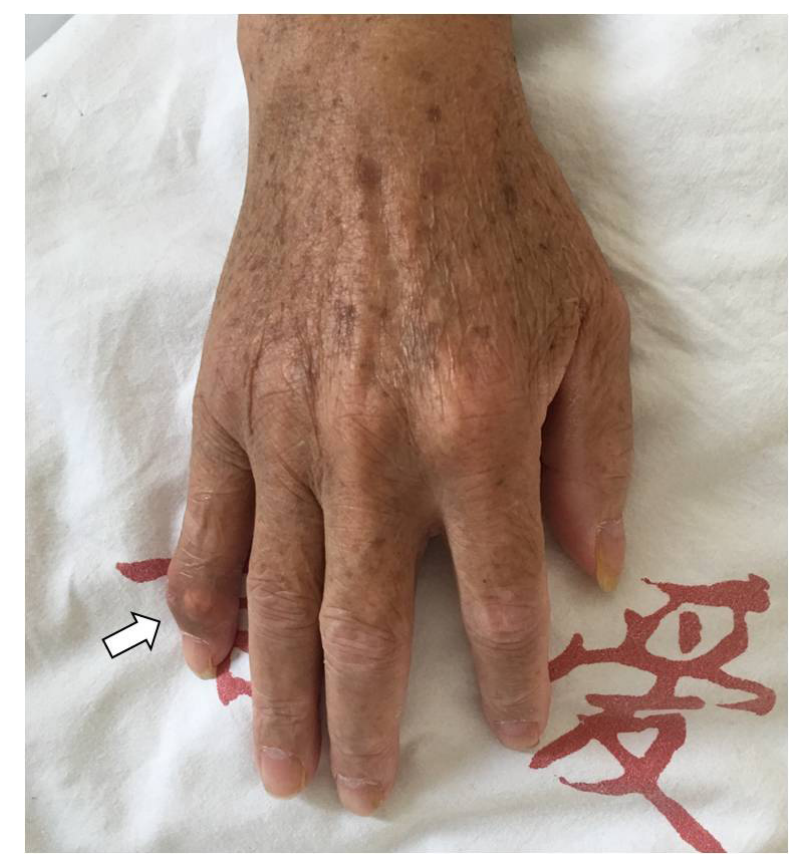

Figure I A picture of the patient's right hand.

Note: The arrow indicates the gouty tophus found at the right little finger.

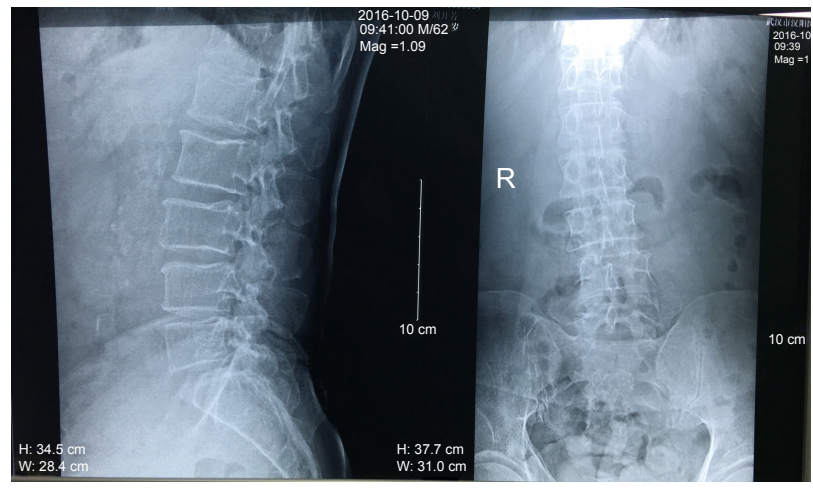

Figure 2 Plain X-ray films of the lumbar spine showing no obvious abnormalities except slight degenerative lumbar scoliosis (anteroposterior view on the left and lateral view on the right).

equina compression (Figure $4 \mathrm{~A}$ and $\mathrm{B}$ ). This collection was of soft-tissue intensity with surrounded reactive high signal on the T1-weighted image sequence (Figure 4A and B). On the T2-weighted images, it appeared relatively hypointense with a high signal in the interior (Figure $4 \mathrm{C}$ and D). Lumbar disc herniations were also found at the level of L2/3 and L4/5.

The patient underwent operation 1 week after admission. After stripping the paravertebral muscles, an amorphous white chalky material was found immediately eroding the facet joint from the L3 to the L4 levels. The L4 lamina was removed to permit adequate exploration of the lesion. The same white chalky material was found in the epidural space of the posterior and lateral spinal canal (Figure 5A). This material was partially encapsulated by fibrous tissue and grossly infiltrated the bone and soft tissue in several areas, which was removed completely with a currette (Figure 5B and C). Surgical stabilization with the screw and rod system was performed after surgical decompression.

Samples of the amorphous material removed during the operation were fixed in $10 \%$ formalin for histological examination. Microscopic examination of the specimen showed granulomatous tissue with structureless coagulative necrosis and fibrinoid necrosis, while the acid-fast stain was negative (Figure 6).

The patient's symptoms improved immediately after the operation. He recovered well without complications and was able to walk easily from the second day postoperation with the assistance of a thoracolumbar orthosis. A written informed consent has been signed by the patient to permit the publication of the case details and any accompanying images.

\section{Discussion}

Tophaceous gout is a common metabolic disorder in which deposition of monosodium urate crystals in the distal joints 
A

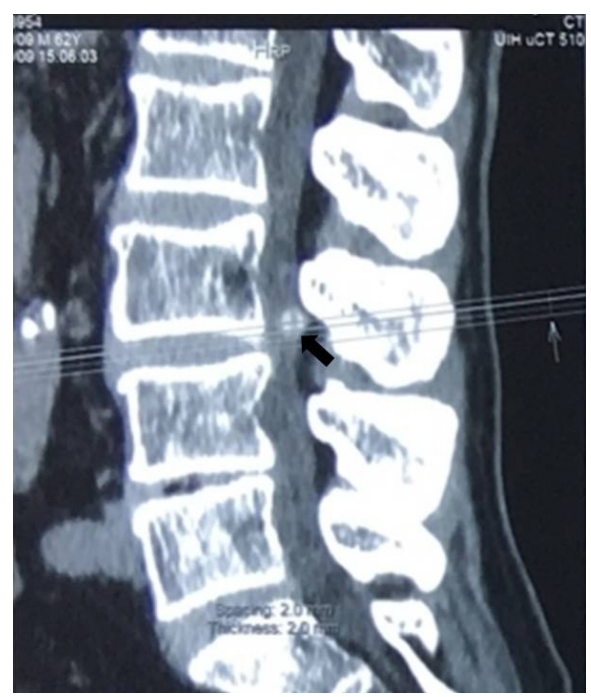

B

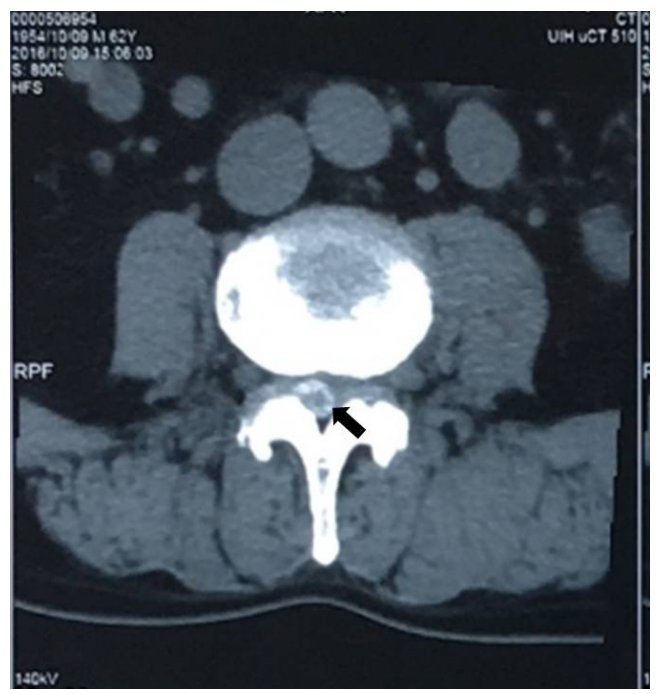

Figure 3 Computed tomography (CT) images of the lower spine.

Notes: The images show a partially calcified, round mass in the spinal canal at level L3/4 (indicated by the arrow in the sagittal tomogram A), with a gas-like low-density nodule in the interior. The mass was shown on the axial tomogram to be situated in the right portion of the spinal canal (indicated by the arrow in B). Spinal stenosis was found at the $L 3 / 4$ accordingly.
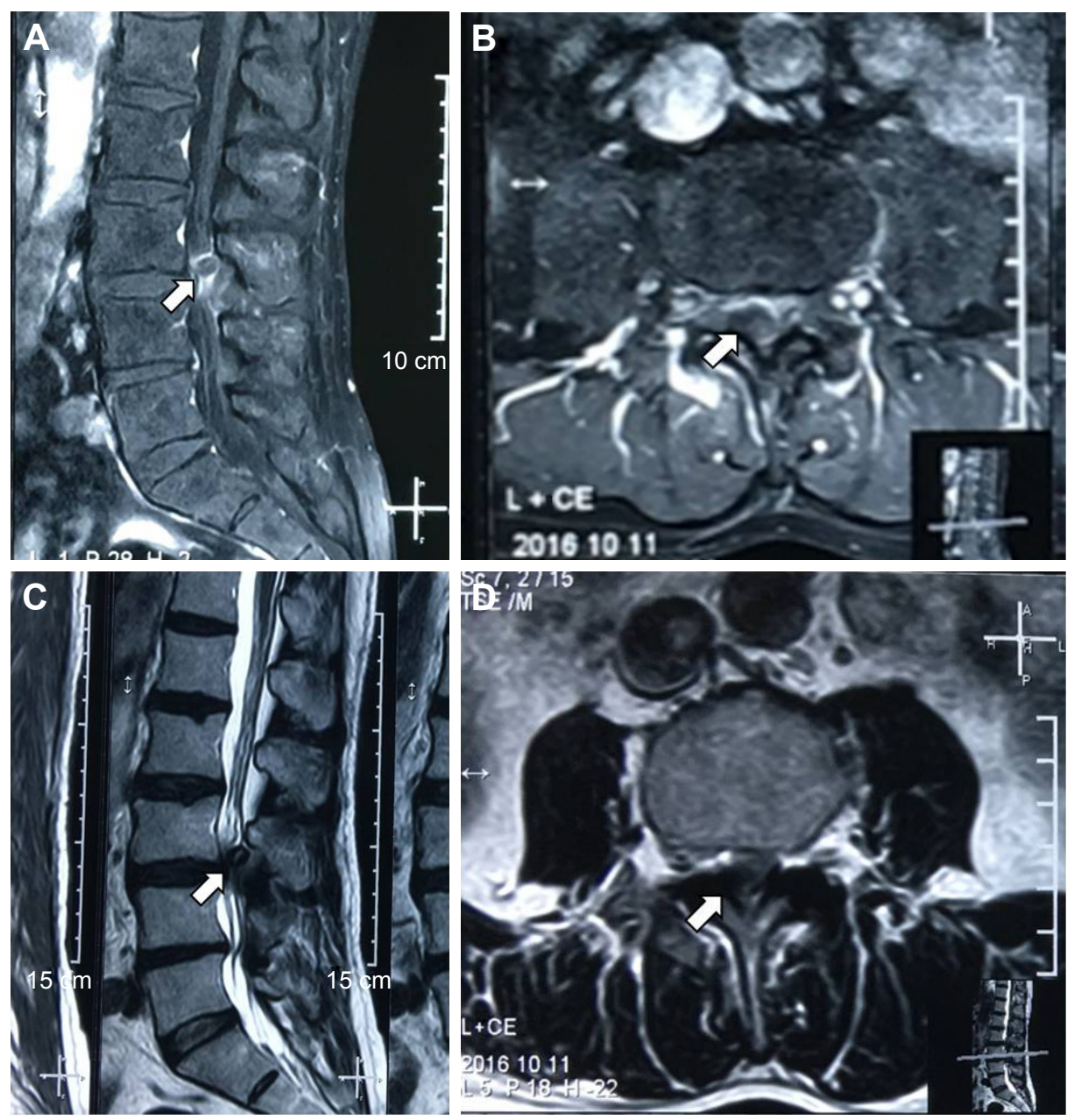

Figure 4 Lumbar spine magnetic resonance imaging (MRI) images demonstrating an abnormal round epidural collection at the L3/4 level, compromising the spinal canal and causing cauda equina compression (indicated by the arrows).

Notes: This collection was of soft-tissue intensity with surrounding reactive high signal on the TI-weighted image sequence (A and B). On the T2-weighted images, it appeared relatively hypointense with a high signal in the interior (C and $\mathbf{D})$. Herniation of the L2-3 and the L4-5 discs was also noted. 

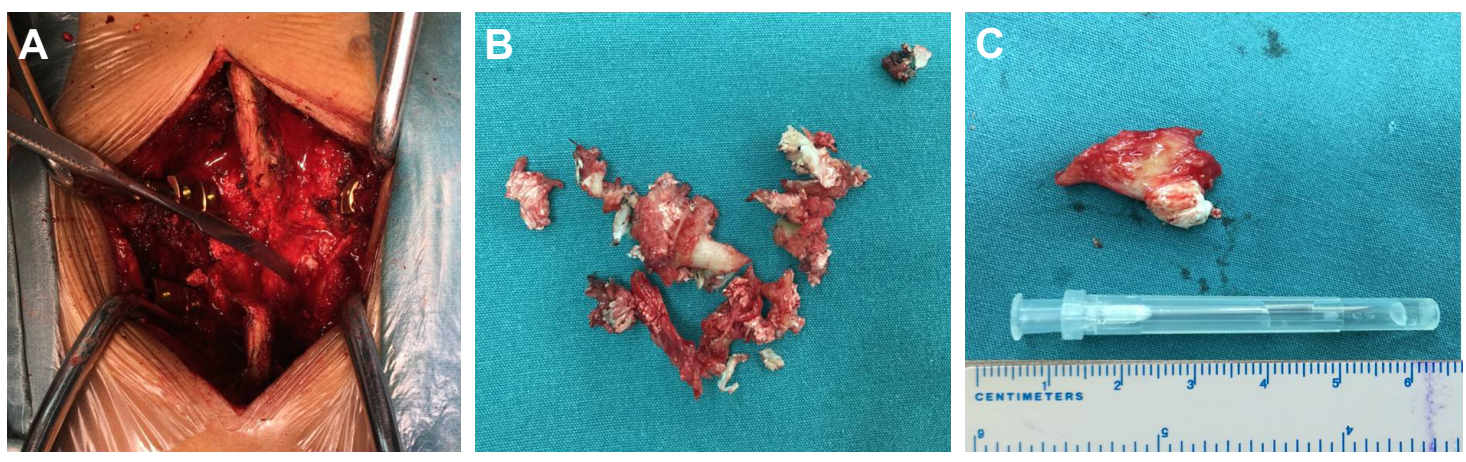

Figure $\mathbf{5}$ Intraoperative pictures showing white chalky material deposited in the epidural space of the posterior and lateral spinal canal (A). This material was partially encapsulated by fibrous tissue and grossly infiltrated the bone and soft tissue in several areas, which was removed completely with a curette (B and C).

of the appendicular skeleton and soft tissues can occur. ${ }^{1}$ The involvement of the axial spine is rare, with only 37 cases of gouty arthritis of the spine having been reported prior to 2001. ${ }^{2}$ The number of cases only increased to 131 in 2015 , and more than half of the cases reported ( 73 cases) were located in the lumbar spine. ${ }^{3}$

There are several factors that may contribute to the development of gouty tophi, including the $\mathrm{pH}$ levels of the surrounding environment, low temperatures, trauma, and the presence of a nucleating agent within the synovial fluid, which can promote the crystallization of previously deposited monosodium urate (MSU). ${ }^{4-6}$

Gout is partly genetic, and many genome-wide studies have uncovered several genes associated with this disease. There are over 30 gene sequence variants commonly found to influence the serum uric acid concentrations, mostly in the SLC2A9, SLC22A12, and ABCG2 genes. ${ }^{7,8} A B C G 2$ plays a central role on extrarenal uric acid excretion. Severe $A B C G 2$ dysfunction particularly increased the risk of early-onset gout. ${ }^{9}$ Genetic analysis may be informative for the assessment of the disease prognosis in individuals with hyperuricemia or established gout, provide information for a personalized lifestyle advice, aid the selection and the dosing of uratelowering therapy, and prevent serious medication adverse effects. ${ }^{10}$ Whether axial gout is associated with differential gene expression is of interest. In our patient case, there was no family history of gout; however, we cannot exclude the possibility of genetic contribution since genetic tests were not performed. Identifying genetic risk factors for axial gout would be beneficial for the early diagnosis of the disease; therefore, more attention should be paid in this area in the future.

The exact mechanism of gouty tophi formation in the axial skeleton is not clear. Volkov et al ${ }^{11}$ suggested that the poor vascularization within the area may be a contributing factor. The patient's hyperlipidemic state, obese body habitus, and minimal physical activity can cause a small caliber vasculature in the axial skeleton, which can lead to inability to adequately filter the uric acid deposited in that area. If the patient had a previous degenerative disc disease (DDD), the acidic $\mathrm{pH}$ and the low oxygen microenvironment will promote uric acid deposition and tophi formation. Our patient also suffered from DDD, suggesting that his axial skeleton harbored the microenvironment required for uric acid formation.
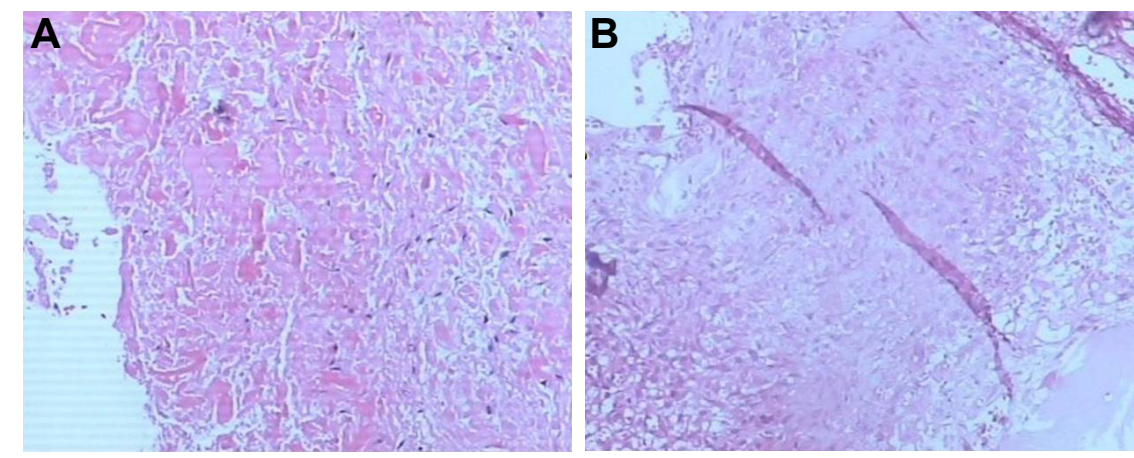

Figure 6 Microscopic examination of the specimen showed granulomatous tissue with structureless coagulative necrosis and fibrinoid necrosis (A and B). Notes: The acid-fast stain was negative. Original magnification $\times 100$. 
According to the literature, spinal tophaceous gout can vary in symptoms as the urate deposits can be formed in different locations. Their appearance can mimic neoplasm or abscess, or they can cause cervical neck pain and spinal instability, frequently seen in degenerative process disorders. ${ }^{11-14}$ The most common symptom is back pain, accounting for $65.4 \%-68.5 \%$ of patients suffering from neurological deficits, including radiculopathy, loss of sensation, motor weakness, bowel/bladder dysfunction, and quadriparesis. ${ }^{3}$ All segments of the spine could be affected by gout, and most of the gout tophi are located in the lumbar spine, followed by the cervical vertebrae., ${ }^{3,15}$ In our case, the main symptom of the patient was back pain, which in combination with intermittent claudication and paresthesia and other symptoms, mimicked the symptoms of lumbar spinal stenosis.

The features of spinal tophaceous gout on plane radiographs are nonspecific, and the abnormalities usually reported include spondylosis, spondylolisthesis, degenerative changes, and diffuse spinal hyperostosis. ${ }^{16,17}$ In other cases, the performance was normal, ${ }^{18}$ like in the case reported in this study. The MRI features of spinal tophaceous gout are also nonspecific. The periarticular deposits containing low signal foci on all MRI image sequences could possibly indicate spinal tophaceous gout, ${ }^{19}$ but this radiological finding cannot differentiate tophaceous gout from other disorders such as disc or vertebral infection, epidural abscess, and rheumatoid arthritis. ${ }^{19}$ Kelly et $\mathrm{al}^{20}$ suggested that gouty tophi could appear as a hypo-intense, homogenous mass associated with a joint on T1- and T2-weighted MRI, which enhances with gadolinium because of vascularized reactive tissue in the tophus. CT characteristics of axial gout are intraarticular and juxtaarticular erosions with sclerotic margins that are denser than the surrounding muscle..$^{12,15,21}$ Other CT findings include degenerative changes, lytic lesions, and spinal stenosis. ${ }^{22-25} \mathrm{We}$ found that it was not easy to diagnose this disease radiographically. Are there any imaging methods with high specificity and accuracy to diagnose spinal tophaceous gout?

A new emerging modality for gout called dual-energy CT (DECT) scanning may be the answer. It was reported to have high sensitivity $(91.9 \%)$ and specificity $(85.4 \%)^{26}$ in identifying gout tophi. DECT scanners capture images at two separate energy levels, compared to the standard single-energy CT, which allows substances of different chemical compositions to appear distinct based on their differential X-ray photon energy. ${ }^{27}$ DECT scans can produce obvious color displays for urate deposits and help to identify subclinical gouty tophi. Furthermore, researchers can measure the tophi's volume by using DECT.$^{28}$ DECT could also be considered during treatment evaluation. Lack of adherence to treatment should be considered when P-urate values vary significantly and when DECT scans over years persistently visualize MSU crystals. ${ }^{29}$ However, DECT has lower sensitivity when restricted to individual crystal-proven gouty joints in nontophaceous disease or individual erosive lesions in tophaceous gout. ${ }^{30}$ At the moment, the high cost of DECT and the lack of training of most radiologists in interpreting the images prevent its widespread use. ${ }^{26}$

Gout is treated with colchicine, nonsteroidal antiinflammatory drugs, or both, to stabilize the acute attacks, and by allopurinol for urate-lowering therapy. ${ }^{31}$ The recommended first-line urate-lowering therapy is xanthine oxidase inhibitors (XOIs). Minimizing uric acid synthesis with XOIs is the preferred mechanism for lowering serum urate levels. Allopurinol and febuxostat are currently the only two US Food and Drug Administration-approved XOIs. If one fails to significantly lower uric acid levels or is poorly tolerated, then the other is considered an appropriate selection. ${ }^{32}$ Uricosuric agents such as probenecid may be used in combination with an XOI or as monotherapy in refractory gout. ${ }^{32,33} \mathrm{New}$ generation uricosurics, notably lesinurad and arhalofenate, in combination with XOIs, show a promising potential in achieving sufficient serum uric acid reduction. ${ }^{34,35}$

Surgical management should be considered and recommended in patients with neurological deterioration in spinal gout. Surgical management includes surgical decompression and surgical stabilization. According to the literature, the patients who underwent surgery had a favorable outcome. ${ }^{36}$ Needle biopsy plays an important role in patients without neurological compromise, as it helps confirmation of diagnosis and the initiation of medical conservative therapy, preventing unnecessary surgical risks. ${ }^{37}$ Regardless of surgical or conservative treatment, compliance with maintenance treatment of gout is mandatory for disease control. Our patient had lower back pain and a progressive lower limb radiation pain for 3 months with subacute deterioration resulting in gait impairment. Surgical decompression and surgical stabilization were necessary since neurological deterioration was identified.

\section{Conclusion}

Cases of patients with spinal gout are rarely presented in a clinical environment. Many doctors do not recognize the condition and make a delayed diagnosis, even in cases of patients with a long history of gout. The mechanism associated with 
axial gout is not yet clear; however, obesity, inactivity, and previous DDD may be the risk factors for spinal tophus. The clinical manifestations are diverse as the urate deposits can be formed in different locations. All segments of the spine could be affected by gout. The differential diagnosis of spinal gout includes spine tumor, epidural abscess, spondylodiscitis, rheumatoid arthritis, and spinal degenerative disease. It is not easy to diagnose this disease radiographically by the routine radiological techniques, but DECT may be a promising method, which needs further study. Examination of a biopsy specimen is undoubtedly the only way to confirm the diagnosis. Surgical management should be considered and recommended in patients with neurological deterioration in spinal gout. The long-term effect of treatment for spinal gout has not been reported, and thus, prospective research is necessary.

\section{Disclosure}

The authors report no conflicts of interest in this work.

\section{References}

1. Mallinson PI, Reagan AC, Coupal T, Munk PL, Ouellette H, Nicolaou S. The distribution of urate deposition within the extremities in gout: a review of 148 dual-energy CT cases. Skeletal Radiol. 2014;43(3): 277-281.

2. Barrett K, Miller ML, Wilson JT. Tophaceous gout of the spine mimicking epidural infection: case report and review of the literature. Neurosurgery. 2001;48(5):1170-1172. discussion 1172-1173.

3. Toprover M, Krasnokutsky S, Pillinger MH. Gout in the spine: imaging, diagnosis outcomes. Curr Rheumatol Rep. 2015;17:70.

4. Dalbeth N, Haskard DO. Mechanisms of inflammation in gout. Rheumatology (Oxford). 2005;44:1090-1096.

5. Pankhania AC, Patankar T, Du Plessis D. Neck pain: an unusual presentation of a common disease. Br J Radiol. 2006;79:537-539.

6. Mekelburg K, Rahimi AR. Gouty arthritis of the spine: clinical presentation and effective treatments. Geriatrics. 2000;55:71-74.

7. Stiburkova B, Miyata H, Zavada J, et al. Novel dysfunctional variant in ABCG2 as a cause of severe tophaceous gout: biochemical, molecular genetics and functional analysis. Rheumatology (Oxford). 2016;55: 191-194.

8. George RL, Keenan RT. Genetics of hyperuricemia and gout: implications for the present and future. Curr Rheumatol Rep. 2013;15(2): 309.

9. Matsuo H, Ichida K, Takada T, et al. Common dysfunctional variants in ABCG2 are a major cause of early-onset gout. Sci Rep. 2013;3:2014.

10. Dalbeth N, Stamp LK, Merriman TR. The genetics of gout: towards personalised medicine? BMC Med. 2017;15(1):108.

11. Volkov A, Rhoiney DL, Claybrooks R. Tophaceous gout of the lumbar spine: case report and review of the literature. Turk Neurosurg. 2015; 25(6):954-958.

12. Beier CP, Hartmann A, Woertgen C, Brawanski A, Rothoerl RD. A large, erosive intraspinal and paravertebral gout tophus. Case report. J Neurosurg Spine. 2005;3(6):485-487.

13. Liu T, Liu H, Zhu T. Thoracic spinal cord compression by extradural tophus: a case report and review of the literature. Spinal Cord Ser Cases. 2015;1:15015.
14. Willner N, Monoranu CM, Stetter C, Ernestus RI, Westermaier T. Gout tophus on an intradural fascicle: a case description. Eur Spine J. 2016;25(suppl 1):162-166.

15. Konatalapalli RM, Demarco PJ, Jelinek JS, et al. Gout in the axial skeleton. J Rheumatol. 2009;36(3):609-613.

16. Chang IC. Surgical versus pharmacologic treatment of intraspinal gout. Clin Orthop Relat Res. 2005;(433):106-110.

17. Tsai CH, Chen YJ, Hsu HC, Chen HT. Bacteremia coexisting with tophaceous gout of the spine mimicking spondylodiscitis: a case report. Spine (Phila Pa 1976). 2009;34(2):E106-E109.

18. Udayakumar D, Kteleh T, Alfata S, Bali T, Joseph A. Spinal gout mimicking paraspinal abscess: a case report. J Radiol Case Rep. 2010;4(6): $15-20$.

19. Hsu CY, Shih TT, Huang KM, Chen PQ, Sheu JJ, Li YW. Tophaceous gout of the spine: MR imaging features. Clin Radiol. 2002;57(10): 919-925.

20. Kelly J, Lim C, Kamel M, Keohane C, O'Sullivan M. Topacheous gout as a rare cause of spinal stenosis in the lumbar region. Case report. J Neurosurg Spine. 2005;2:215-217.

21. Zheng ZF, Shi HL, Xing Y, Li D, Jia JY, Lin S. Thoracic cord compression due to ligamentum flavum gouty tophus: a case report and literature review. Spinal Cord. 2015;53(12):881-886.

22. Yamamoto M, Tabeya T, Masaki Y, et al. Tophaceous gout in the cervical spine. Intern Med. 2012;51:325-328.

23. Fraser JF, Anand VK, Schwartz TH. Endoscopic biopsy sampling of tophaceous gout of the odontoid process. Case report and review of the literature. J Neurosurg Spine. 2007;7(1):61-64.

24. Popovich T, Carpenter JS, Rai AT, Carson LV, Williams HJ, Marano GD. Spinal cord compression by tophaceous gout with fluorodeoxyglucose-positron-emission tomographic/MR fusion imaging. AJNR Am J Neuroradiol. 2006;27(6):1201-1203.

25. Yoon JW, Park KB, Park H, et al. Tophaceous gout of the spine causing neural compression. Korean J Spine. 2013;10(3):185-188.

26. Hu HJ, Liao MY, Xu LY. Clinical utility of dual-energy CT for gout diagnosis. Clin Imaging. 2015;39(5):880-885.

27. Nicolaou S, Liang T, Murphy DT, Korzan JR, Ouellette H, Munk P. Dual-energy CT: a promising new technique for assessment of the musculoskeletal system. AJR Am J Roentgenol. 2012;199(5 suppl): S78-S86.

28. Choi HK, Al-Arfaj AM, Eftekhari A, et al. Dual energy computed tomography in tophaceous gout. Ann Rheum Dis. 2009;68:1609-1612.

29. Christensen HD, Sheta HM, Morillon MB, Hansen IM. Tophaceous gout in an anorectic patient visualized by dual energy computed tomography (DECT). Am J Case Rep. 2016;17:494-498.

30. Baer AN, Kurano T, Thakur UJ, et al. Dual-energy computed tomography has limited sensitivity for non-tophaceous gout: a comparison study with tophaceous gout. BMC Musculoskelet Disord. 2016;17:91.

31. Richette P, Bardin T. Gout. Lancet. 2010;375:318-328.

32. Khanna D, Fitzgerald JD, Khanna PP, et al. 2012 American College of Rheumatology guidelines for management of gout. Part 1: systematic nonpharmacologic and pharmacologic therapeutic approaches to hyperuricemia. Arthritis Care Res (Hoboken). 2012;64:1431-1446.

33. Richette P, Doherty M, Pascual E, et al. 2016 updated EULAR evidencebased recommendations for the management of gout. Ann Rheum Dis. 2017;76(1):29-42.

34. Pascart T, Richette P. Current and future therapies for gout. Expert Opin Pharmacother. 2017;18(12):1201-1211.

35. Terkeltaub R. Emerging uricosurics for gout. Expert Rev Clin Pharmacol. 2017;10:247-249.

36. Elgafy H, Liu X, Herron J. Spinal gout: a review with case illustration. World J Orthop. 2016;7(11):766-775.

37. Hou LC, Hsu AR, Veeravagu A, Boakye M. Spinal gout in a renal transplant patient: a case report and literature review. Surg Neurol. 2007; 67(1):65-73. discussion 73. 
Therapeutics and Clinical Risk Management

Dovepress

\section{Publish your work in this journal}

Therapeutics and Clinical Risk Management is an international, peerreviewed journal of clinical therapeutics and risk management, focusing on concise rapid reporting of clinical studies in all therapeutic areas outcomes, safety, and programs for the effective, safe, and sustained use of medicines. This journal is indexed on PubMed Central, CAS,
EMBase, Scopus and the Elsevier Bibliographic databases. The manuscript management system is completely online and includes a very quick and fair peer-review system, which is all easy to use. Visit http://www.dovepress.com/testimonials.php to read real quotes from published authors.

Submit your manuscript here: http://www.dovepress.com/therapeutics-and-clinical-risk-management-journal 